Document downloaded from:

http://hdl.handle.net/10251/124223

This paper must be cited as:

Carpitella, S.; Ocaña-Levario, SJ.; Benítez López, J.; Certa, A.; Izquierdo Sebastián, J. (2018). A hybrid multicriteria approach to GPR image mining applied to water supply system maintenance. Journal of Applied Geophysics. 159:754-764. https://doi.org/10.1016/j.jappgeo.2018.10.021

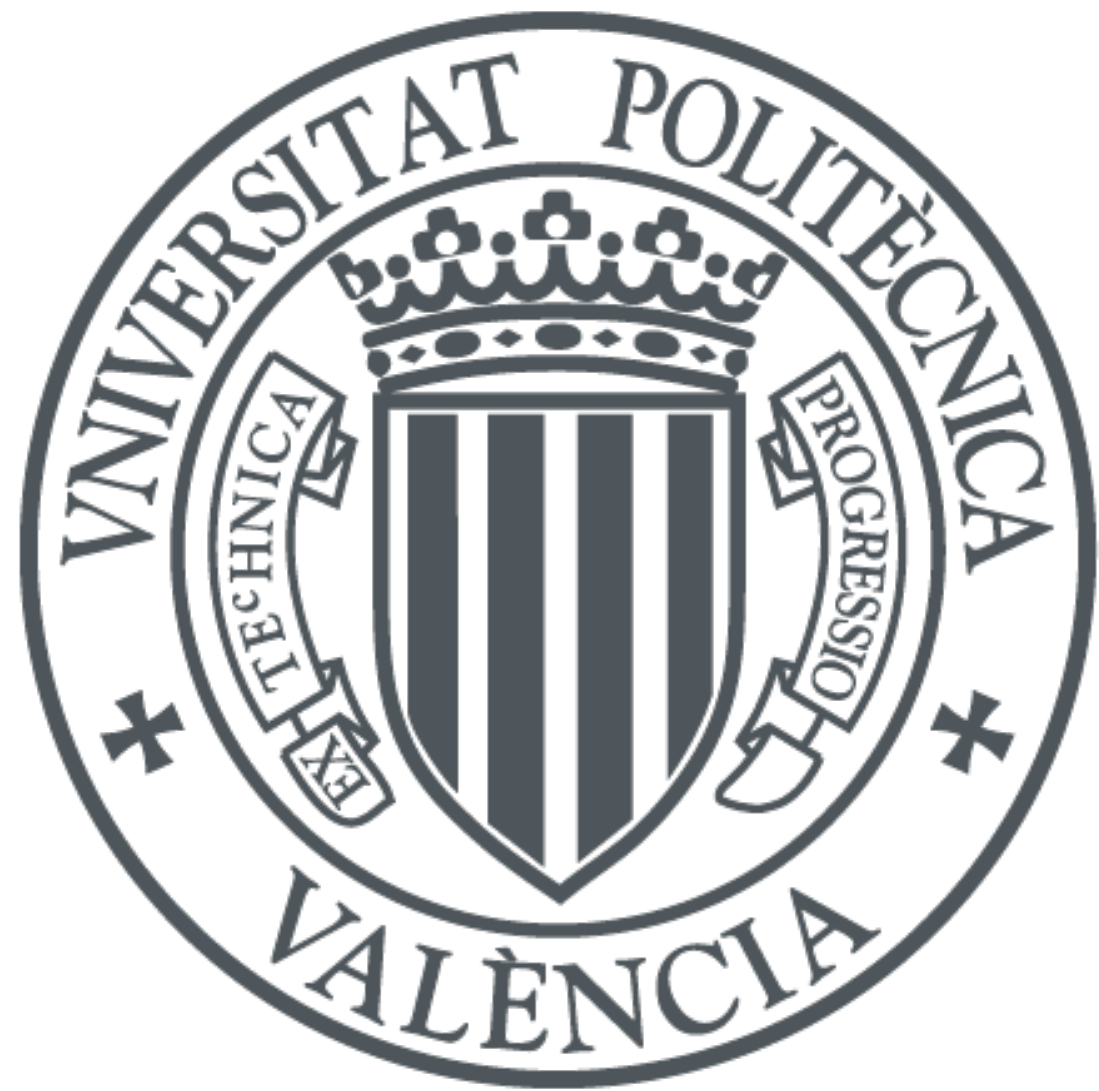

The final publication is available at

http://doi.org/10.1016/j.jappgeo.2018.10.021

Copyright Elsevier

Additional Information 


\title{
A hybrid multi-criteria approach to GPR image mining applied to water supply system maintenance
}

\author{
Silvia Carpitella ${ }^{1,2}$, Silvia J. Ocaña-Levario ${ }^{2}$, Julio Benítez ${ }^{2}$, Antonella Certa1 ${ }^{1}$ Joaquín Izquierdo² \\ ${ }^{1}$ Dipartimento dell'Innovazione Industriale e Digitale (DIID), Ingegneria Chimica, Gestionale, Informatica, Meccanica, \\ Università degli Studi di Palermo, Palermo, Italy \\ ${ }^{2}$ Instituto de Matemática Multidisciplinar, Universitat Politècnica de València, Valencia, Spain
}

\begin{abstract}
Data processing techniques for Ground Penetrating Radar (GPR) image mining provide essential information to optimize maintenance management of Water Supply Systems (WSSs). These techniques aim to elaborate on radargrams in order to produce meaningful graphical representations of critical buried components of WSSs. These representations are helpful non-destructive evaluation tools to prevent possible failures in WSSs by keeping them adequately monitored. This paper proposes an integrated multi-criteria decision making (MCDM) approach to prioritize various data processing techniques by means of ranking their outputs, namely their resulting GPR image representations. The Fuzzy Analytic Hierarchy Process (FAHP) is applied to weight various evaluation criteria, with the purpose of managing vagueness and uncertainty characterizing experts' judgments. Then, the ELimination Et Choix Traduisant la RÉalité III (ELECTRE III) method is used to obtain the final ranking of alternatives. A real case study, focusing on a set of four GPR images as outputs of different data processing techniques, is presented to prove the usefulness of the proposed hybrid approach. In particular, the GPR images are ranked according the evaluation of five criteria namely visualization, interpretation, identification of features, extraction of information and affordability. The findings offer a structured support in selecting the most suitable data processing technique(s) to explore WSS underground. In the presented case, two options, namely the variance filter and the subtraction methods, offer the best results.
\end{abstract}

Keywords: GPR, radargrams, Water Supply Systems, FAHP, ELECTRE III

\section{Introduction and literature review}

Water Supply Systems (WSSs) support many daily human activities and, for this reason, their full availability has to be assured. A sudden lack of hydraulic supply may cause enormous inconveniences, both in civil and industrial environments. For this reason, the activities of maintenance for WSSs have critical importance, and interventions have to be adequately planned and implemented. Firstly, various parts of the networks need to be monitored and kept under control. Non-destructive techniques (NDTs) are useful tools of inspection to explore and obtain information about the underground without damaging it. NDTs make it easy the inspection of possible damages and the overall evaluation of WSSs, with the aim of optimizing maintenance and costs.

A wide number of NDTs are reported in the literature (Liu et al., 2013; Hao et al., 2012) to locate damages in WSSs, the most popular being acoustic methods, thermography and ground penetrating radar (GPR) (Demirci et al., 2012; Dong et al., 2011). In particular, the GPR technique is more effective than the acoustic methods in locating water leaks occurring in plastic pipes (Bimpas et al., 2013). It is also more flexible than thermography approaches because it can be used in the various seasons of the year without being affected by temperature variations (Ayala-Cabrera et al., 2013).

Moreover, the GPR technique reveals to be a useful tool in easily exploring hidden elements (Hoarau et al., 2017; Gurbuz et al., 2012; Porsani et al., 2006) by means of radargrams. Radargrams provide graphical representation of contrasts existing between specific elements and the surrounding ground, due to their different dielectric characteristics (Crocco et al., 2010). The main difficulty in using radargrams derives from the big volume of information and the complexity of data interpretation, being necessary a high level of ability and experience by the involved personnel (Ayala-Cabrera et al., 2011; Thomson et al., 2009). For this reason, a plethora of process and analysis methods have been developed. These methods filter and mine GPR images to improve data visualization, with the aim of effectively identifying abnormal situations occurring underground.

Beyond the analysis of raw images (Hunaidi and Giamou, 1998), this paper uses three image processing techniques, namely: multi-agent system, subtraction and variance filter. The former (Ayala-Cabrera et al., 2013) uses a multi-agent based system to identify elliptical shapes related to abnormal conditions in the system. The second (Ocaña-Levario, 2014; Ayala-Cabrera et al., 2014) proposes a subtraction between two GPR images in 
order to discover hidden features in the explored area. Lastly, the latter (Ocaña-Levario et al., 2016) applies the socalled variance filter to raw GPR images to analyse data variability.

This paper deals with the possibility of managing results derived from the mentioned techniques through such tools as multi-criteria decision making (MCDM) methods. These tools are useful in supporting various kinds of decision problems (Carpitella et al., 2017a; Nikas et al., 2018) and, as expressed by Kumar et al. (2017), their crucial role is widely recognized in the literature. Mulliner et al. (2016) recommend these methods to achieve successful outcomes. In fact, various evaluation criteria, sometimes conflicting with each other, need to be taken into account for making decisions. The authors consider the support given by MCDM methods as valuable and capable of managing both qualitative and quantitative aspects when an evaluation concerning a set of alternatives is required.

Mousavi-Nasab and Sotoudeh-Anvai (2017) underline the potential of MCDM methods to significantly improve complex decision processes. Their research proposes a comprehensive MCDM-based framework to deal with material selection problems. Løken (2007) highlights the high suitability of MCDM methods to face energy planning problems, when many decision makers and criteria are involved. Given that each method has both advantages and drawbacks, the authors recognize the combination of more than one method as a really good practice. As an example, Wang et al. (2016) discuss a case study centred on a facility layout selection problem proposing a hybrid approach based on the following methods: Simple Additive Weighting (SAW), Techniques for Order Preference by Similarity to an Ideal Solution (TOPSIS) (Certa et al., 2013a) and Grey Relational Analysis (GRA).

Among the wide number of MCDM methods existing in the literature (Sipahi and Timor, 2010), the most popular is the Analytic Hierarchy Process (AHP) technique, developed by Saaty (1977). The AHP easily carries out a ranking of decision alternatives (Chen et al., 2014). The method is able to calculate the vector of weights of involved criteria on the basis of the opinions formulated by a single expert or a group of decision makers. However, Büyüközkan et al. (2011) observe the inability of the AHP in correctly reflecting the vagueness of the decision makers' perception and thus, in many real cases, linguistic assessment is necessary, instead of just crisp numbers, to represent the real situation.

A further - and possibly more reliable - development of the AHP method consists in a fuzzy extension. The Fuzzy Analytic Hierarchy Process (FAHP), firstly proposed by Van Laarhoven and Pedrycz (1983), takes advantage of the fuzzy set theory (Zadeh, 1965; Klir and Yuan, 1995) for adequately managing uncertainty often characterizing judgments expressed by experts. Kubler et al. (2016) present a wide review of many applications of FAHP. The authors analyse 190 papers published between the years 2004 and 2016 and classify them on the basis of their main features and application fields. According to the survey carried out by the authors, the FAHP is commonly used in the literature for calculating criteria weights and then it is combined with other MCDM methods, for instance FTOPSIS (Kutlu and Ekmekçioğlu, 2012; Büyüközkan and Çif̧̧i, 2012), to rank the alternatives under evaluation.

In particular, FAHP may be well integrated with methods belonging to the ELimination Et Choix Traduisant la RÉalité (ELECTRE) family (Figueira et al., 2013). They support analysts in a wide range of decision problems (Muñoz-Porcar et al., 2015; Abedi et al., 2012; Hatami-Marbini and Tavana, 2011; Hokkanen et al., 1995; Jun et al., 2014; Proulx et al., 2007) and enable to accomplish various kinds of results including selection of the best option, and ranking and clustering of alternatives. Examples of integration between FAHP and ELECTRE may be found in the literature. Kaya and Kahraman (2011) propose a combined FAHP-ELECTRE approach to evaluate the environmental impact in the context of urban industrial planning. Ka (2011) suggests the same combination to make decisions concerning the optimal selection among dry ports construction projects.

Among the different ELECTRE versions, the ELECTRE III effectively permits to rank alternatives related to different contexts (Certa et al., 2013b; Certa et al., 2009; La Scalia et al., 2015). As shown by Govindan and Jepsen (2016), ELECTRE III is the most used method of the ELECTRE family and the main fields of its application are natural resources and environmental management, energy management, and water management.

Dealing with the field of maintenance of water supply networks, the present research seeks to prioritize techniques of data processing to prevent and discover eventual damages or water losses occurring in buried pipes. Such evaluation is supported by means of an integrated MCDM approach. Actually, this paper is a substantial extension of a previous work (Carpitella et al., 2017b), in which the ELECTRE I method was proposed to select the best alternative belonging to a set of four GPR images resulting from the application of four different data processing techniques. Four crisp evaluation criteria were considered, namely visualization, interpretation, identification of features, and extraction of information. We are now interested in carrying out, in a fuzzy context, a further in-depth analysis of various data processing methods and in drawing up a ranking of resulting GPR images by considering a fifth evaluation criteria, namely the affordability of the analyses. To such aim, an integration process between the FAHP and the ELECTRE III methods is proposed. To the best of the authors' knowledge, it is the first time that such a hybrid approach is suggested to rank GPR images of WSSs with the aim of increasing the quality of maintenance management. Moreover, by analysing the characteristics of various data processing 
techniques, we expect that a more reliable and accurate method may be selected as the best trade-off, since maintenance is crucial to guarantee a continuous functioning of systems. The FAHP reveals to be helpful to calculate criteria weights by effectively managing uncertainty of experts' opinions. In its turn, the ELECTRE III provides decision makers with a ranking of alternatives and, consequently, with a proper support to optimize maintenance of WSSs, taking also into account the uncertainty of data by means of the use of appropriate thresholds.

The remainder of the paper is organized as follows. Section 2 illustrates some useful data processing techniques, aimed at elaborating on GPR images of WSSs. In particular, beyond the raw material analysis, the following techniques are considered: multi-agent based pre-processing algorithm, subtraction method and variance filter. Section 3 presents the proposal of integration between the two mentioned MCDM methods. The steps to apply the FAHP and the ELECTRE III methods are also described. Section 4 discusses a real case study in which GPR images obtained from the application of the above-mentioned data processing techniques are considered and then ranked. Section 5 closes the research with the conclusions.

\section{Data processing techniques to handle GPR images from WSSs}

This section aims to briefly describe some GPR image processing methods and how to apply them to handle GPR images obtained from surveys in WSSs. These results graphically represent critical parts (either hidden infrastructure or developed abnormalities, such as leaks) of the WSS under analysis and provide analysts with important information concerning scheduling of maintenance activities. The ranking of the obtained images is a helpful driver to choose the more suitable technique as a trade-off among different evaluation criteria.

The procedures used to carry out diverse data processing techniques are described next. In Carpitella et al. (2017b) images coming from four data processing techniques were considered, namely, the raw material analysis (note that no processing is used here), the multi-agent based pre-processing algorithm, the subtraction method, and the variance filter. Their descriptions are herein summarized.

\subsection{Raw images}

This kind of analysis cannot be considered as a proper method. In fact, it works directly on data matrices obtained via GPR surveys. However, these analyses are widely used to identify various features in the networks (Ocaña-Levario, 2014), which have proved to be sometimes successful.

Raw images are sets of data obtained by means of GPR surveys, and visualized as radargrams. These data are stored in raw radargram matrices, $M R_{j}, j=1, \ldots, s$ corresponding to the $s$ performed measurements. These matrices are made up of $m$-vectors, $b(j)$, where $k=1, \ldots, n$ denotes the trace of each radargram. Traces represent changes in depth of electromagnetic properties of the soil. In particular, matrices can be represented by columns, $M R_{j}=$ $\left(b_{1}^{(j)}, b_{2}^{(j)}, \ldots, b_{n}^{(j)}\right)$. The length $m$ of vector $b_{k}^{(j)}$ corresponds to the volume of registered data for each trace $k$. It depends on the characteristics of the signal emitted by the used equipment.

We can consider raw images as those obtained from a preliminary inspection, in which hyperbolae are mainly sought. Hyperbolae indicate the likely existence of objects or abnormalities in WSSs, suggesting the implementation of further and deeper analyses. We use analyses of raw images for comparison purposes, aiming at showing various difficulties of visualization when compared with images obtained from other methods.

\subsection{Multi-agent-based pre-processing algorithm}

This GPR image pre-processing algorithm was proposed in (Ayala-Cabrera et al., 2013) and was termed agent race. The algorithm is based on the game theory and uses the multi-agent paradigm (Shoham and Leyton-Brown, 2009).

The input of this algorithm is the resulting radargram of the GPR prospection, which consists of an $m \times n$-sized matrix. The $n$ traces of length $m$ generated are used as parallel tracks for the $n$ agents to run. The race is an endurance test for the competing agents, the prize for each agent being a movement step forward for each performed effort. Those efforts are based on wave amplitude value changes in each column of the radargram. The agent race includes two phases: a) warming-up, and b) competition. The race takes the following total time:

$$
t t=t w+t r=m
$$

$t w$ being the warming-up time and $t r$ the competition time. The displacements of the agents during time $t r$ are conditioned by the trend change of the wave amplitude on the trace that is being run. The race ends when time $t t$ has elapsed, and the race winner is the agent who has obtained the largest displacement during this time.

The first output (Output $\mathrm{A}$ in Figure 1) of this process consists of an $m 1 \times n$ matrix, $m 1$ being the maximum number of displacements. The columns in this matrix describe the movement of the agents related to the 
competition. The movements obtained by the agents are called time lines. At the end of the race, time lines are sorted according to the time spent by each agent. Finally, these time lines are normalized, thus obtaining the second output (Output B in Figure 1), which is the final visualization matrix of this method.

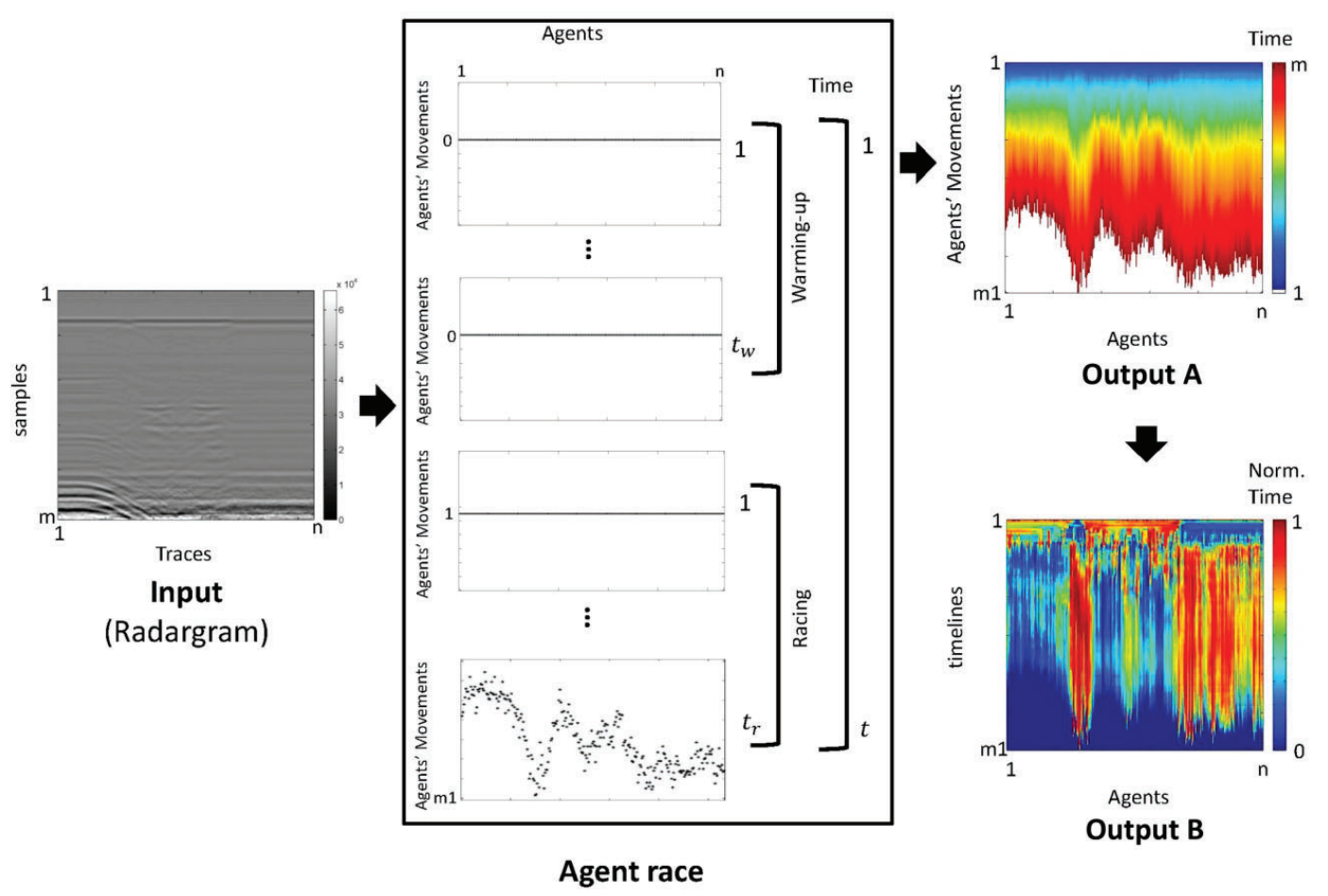

Fig. 1. Scheme for the agent-race algorithm

\subsection{Subtraction method}

The strengths of this method are both its simplicity of use and its effectiveness in obtaining results. Its application consists in performing a subtraction between a reference image and a GPR image obtained upon inspection. This kind of subtraction is aimed at highlighting the main features of interest.

The input of this method (see Figure 2) is the raw image (raw matrix) obtained from the GPR survey, denoted by $M R_{j}$, previously described in section 2.1. Moreover, a new image (i.e. matrix) has to be created, that is called reference matrix or white matrix, $M W$. The calculation of this matrix is developed as follows. From the set of measurements, $\left\{M R_{1}, \ldots, M R_{S}\right\}$, an average column vector of size $m$, called $b c$, is calculated:

$$
b c=\frac{\sum_{j=1}^{s} \sum_{k=1}^{n} b(\dot{k})}{n \cdot s}
$$

Matrix $M W$ is built by consecutively accumulating this vector $n$ times. Matrix $M C_{j}$, called subtraction matrix, is calculated as:

$$
M C_{j}=a b s\left(M R_{j}-M W\right)
$$

The images obtained through these matrices are analysed in detail, to iteratively select a range of colour to highlight significant features in the images. The purpose consists in exploring information concerning certain system components and its boundary conditions (Ayala-Cabrera et al., 2014). 


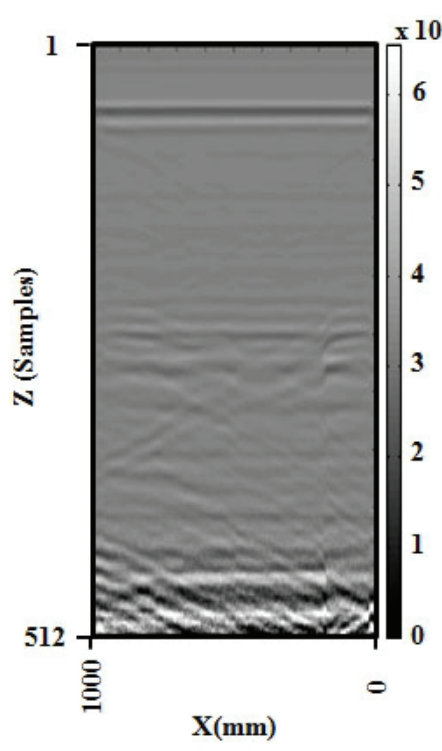

(a)

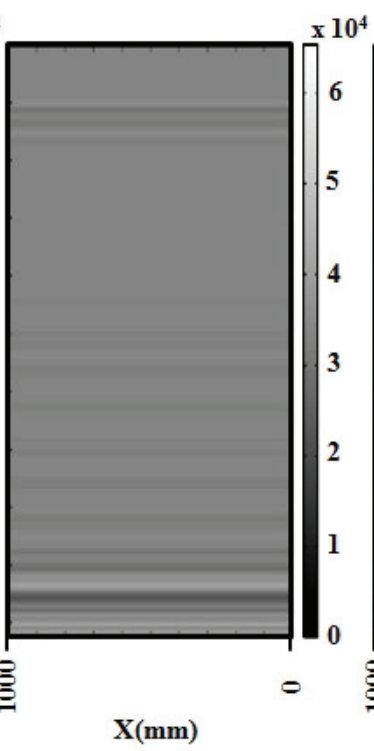

(b)

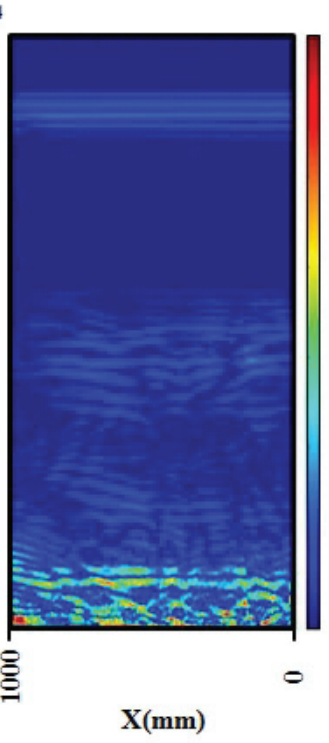

(c)

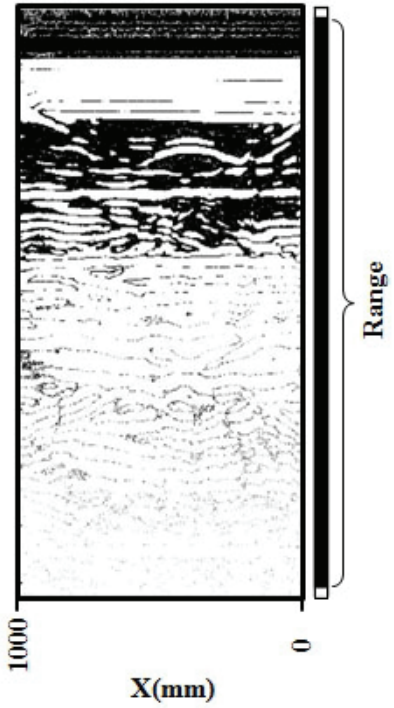

(d)

Fig. 2. a) Raw image, $\boldsymbol{M} \boldsymbol{R}_{\boldsymbol{j}}$ matrix, (b) white matrix, $\boldsymbol{M} \boldsymbol{W}$, (c) subtraction matrix, $\boldsymbol{M} \boldsymbol{C}_{\boldsymbol{j}}$, and (d) selection of color range for the subtraction matrix

\subsection{Variance filter}

The variance filter enables to demark boundaries among different materials existing in images, highlighting them and allowing a clearer visualization of changes. This helps in the location and posterior extraction of abnormalities.

A variance filter is directly applied to GPR images, and modifies the images according to data variability. The basic principle of the variance filter consists in calculating the variance around each pixel $u_{i j}$ of the image. Firstly, the window size (number of pixels to work with) is defined. In our study, the proposed size of the window has been selected after several tests. The size results to be $3 \times 1$, which is the best result with relation to the visualization of images. The variance filter formulation is defined by

$$
\begin{aligned}
\bar{u}_{i j} & =\frac{1}{n} \sum_{i=1}^{n} u_{i j} ; \\
\sigma_{i j}^{2} & =\frac{1}{n} \sum_{i=1}^{n}\left(u_{i j}-\bar{u}_{i j}\right)^{2} .
\end{aligned}
$$

The mean, defined by (4), is firstly estimated for the chosen window; $n$ is herein the number of pixels in our window and $u_{i j}$ is the pixel value of the GPR image. Secondly, the variance $\sigma_{i j}^{2}(5)$ is calculated with the pixels inside the selected window and the value obtained in (4). The result is associated to the centre pixel of the window in a new image, and this is repeated for all pixels of the initial GPR image, giving a new image of lower dimension.

\section{Integration of MCDM methods to manage results of data processing analyses}

In this section, a structured framework that combines two MCDM methods is proposed. Integration of these methods aims to prioritize different data processing techniques by ranking their relative outputs, i.e. resulting GPR images. The achieved solution offers effective support since it represents a valid tool to optimize the maintenance management of WSSs. Indeed, a highly reliable technique visually representing critical parts of the network can be easily selected and applied, depending on the involved evaluation criteria. The proposed approach is created through the integration of FAHP and ELECTRE III methods. In the present section these methods are described and successively applied to a real case study.

\subsection{The FAHP technique}

The fuzzy set theory represents a valid support to manage uncertainty affecting human judgments. Indeed, linguistic variables could be expressed through fuzzy numbers rather than crisp values, and have associated a degree of membership, $\mu(x)$, varying between 0 and 1 . There are various types of fuzzy numbers. The most common ones are triangular fuzzy numbers (TFN) and trapezoidal fuzzy numbers (TrFN) (Zimmermann, 1985; 
Kubler et al., 2016). A generic TFN (6) $\tilde{n}$ is defined by three numerical values, $a, b$ and $c$, respectively called the lower, the medium and the upper value of the fuzzy number, where $a \leq b \leq c$. A generic $\operatorname{TrFN}(7) \tilde{m}$ is defined by four numerical values, $d, e, f$ and $g$, respectively called the lower, the two medium and the upper values of $\tilde{m}$; here $d \leq e \leq f \leq g$ :

$$
\begin{aligned}
& \tilde{n}=(a, b, c) ; \\
& \tilde{m}=(d, e, f, g) .
\end{aligned}
$$

Algebraic operations can be accomplished among fuzzy numbers. For instance, considering two TFNs $\tilde{n}_{1}$ and $\tilde{n}_{2}$, the following operations (8-10) may be defined:

$$
\begin{aligned}
& \tilde{n}_{1} \oplus \tilde{n}_{2}=\left(a_{1}+a_{2}, b_{1}+b_{2}, c_{1}+c_{2}\right) ; \\
& \tilde{n}_{1} \odot \tilde{n}_{2}=\left(a_{1} \times a_{2}, b_{1} \times b_{2}, c_{1} \times c_{2}\right) ; \\
& \tilde{n}_{1}^{-1}=\left(\frac{1}{c_{1}}, \frac{1}{b_{1}}, \frac{1}{a_{1}}\right) .
\end{aligned}
$$

Based on the use of fuzzy numbers, the FAHP method is the fuzzy development of the AHP technique, and its application can be summarized through this three following steps (Durán and Aguiló, 2006):

- building the hierarchy structure that represents the problem under analysis;

- collecting fuzzy pairwise comparisons with relation to decision alternatives with respect to each evaluation criterion;

- ranking alternatives to prioritize them or to select the best one.

Concerning the collection of fuzzy pairwise comparisons, the purpose is to build a fuzzy pairwise comparison matrix (FPCM), $\tilde{X}$. In this matrix, the linguistic judgments attributed by the expert(s) correspond to fuzzy numbers. For example, given a number $n$ of criteria (or alternatives) to be pairwise compared, one can build the square reciprocal matrix:

$$
\tilde{X}=\left[\begin{array}{ccc}
\tilde{x}_{11} & \cdots & \tilde{x}_{1 n} \\
\vdots & \ddots & \vdots \\
\tilde{x}_{n 1} & \cdots & \tilde{x}_{n n}
\end{array}\right]
$$

in which a generic element $\tilde{x}_{i j}$ expresses the degree of preference of criterion (or alternative) $i$ with respect to criterion (or alternative) $j$ with a certain level of uncertainty. Moreover, reciprocity implies that for each pairwise comparison judgment $\tilde{x}_{i j}=\left(x_{1}, x_{2}, x_{3}\right)$ one has that $\tilde{x}_{j i}=\left(\frac{1}{x_{3}}, \frac{1}{x_{2}}, \frac{1}{x_{1}}\right)$.

As said before, linguistic variables are used by an analyst (or decision maker) to express pairwise comparisons about the relative importance between two elements. In particular, these variables refer to the fuzzy version of the Saaty scale, shown in Figure 3, and can be stated as: equal (EQ), moderate (M), strong (S), very strong (VS) and extreme (EX) importance.

The associated TFNs are respectively: $(1,1,2),(2,3,4),(4,5,6),(6,7,8)$ and $(8,9,9)$. The TFNs $(1,2,3),(3,4,5)$, $(5,6,7)$ and $(7,8,9)$ correspond to the intermediate values.

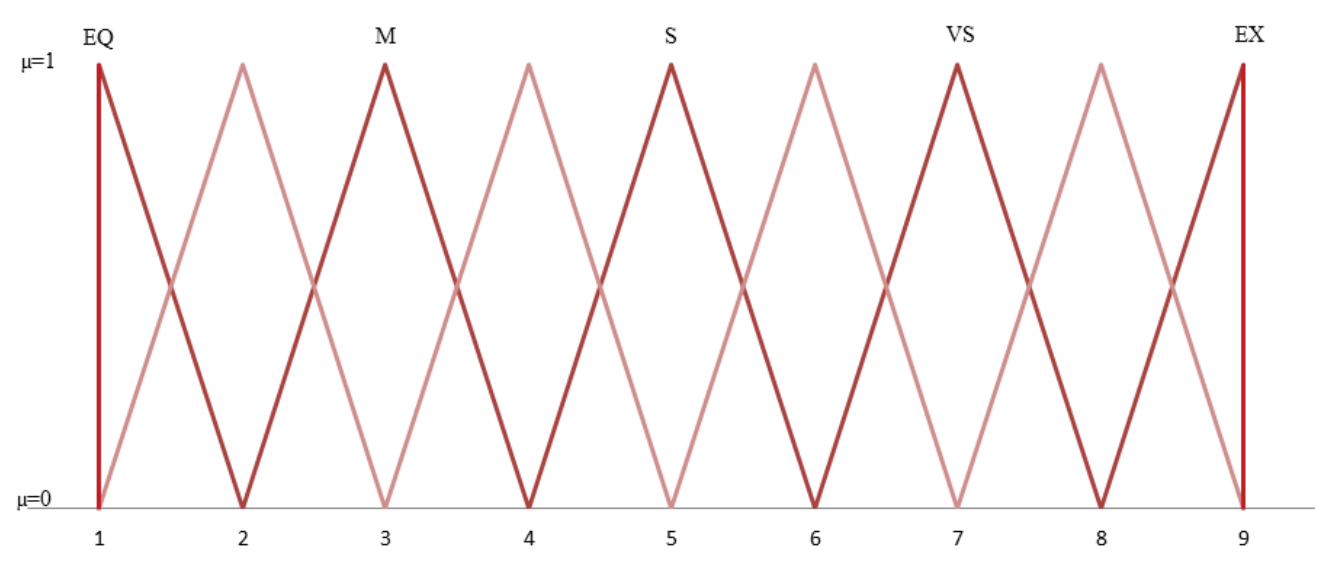

Fig. 3. Fuzzy version of the Saaty scale 
Once built the FPCM $\tilde{X}$, several approaches are proposed in the literature to obtain the relative weights. In particular, Chang (1996) proposes to derive crisp weights from the matrix, by exploiting the extent analysis method. The value of fuzzy synthetic extent (12) with relation to the $i^{\text {th }}$ element of the matrix $\tilde{X}$ can be calculated as follows:

$$
S_{i}=\sum_{j=1}^{m} \tilde{x}_{i j} \odot\left[\sum_{i=1}^{n} \sum_{j=1}^{m} \tilde{x}_{i j}\right]^{-1}
$$

being, in our case, $n=m$ since the FPCM $\tilde{X}$ is a square matrix.

Let us consider two fuzzy pairwise comparisons, e.g. two TFNs noted as $\tilde{n}_{1}=\left(a_{1}, b_{1}, c_{1}\right)$ and $\tilde{n}_{2}=\left(a_{2}, b_{2}, c_{2}\right)$. We are interested in establishing the degree of possibility that $\tilde{n}_{1} \geq \tilde{n}_{2}$, defined as (Kutlu and Ekmekçioğlu, 2012):

$$
V\left(\tilde{n}_{1} \geq \tilde{n}_{2}\right)=\mu\left(x^{*}\right)= \begin{cases}1 & \text { if } b_{1} \geq b_{2} \\ 0 & \text { if } a_{2} \geq c_{1} \\ \frac{a_{2}-c_{1}}{\left(b_{1}-c_{1}\right)-\left(b_{2}-a_{2}\right)} & \text { otherwise }\end{cases}
$$

where $x^{*}$ is the ordinate of the highest intersection point $P$ between $\mu_{n_{1}}$ and $\mu_{n_{2}}$, as we can observe in Figure 4 . In order to compare the two TFNs $\tilde{n}_{1}$ and $\tilde{n}_{2}$, it is necessary to calculate both values $V\left(\tilde{n}_{1} \geq \tilde{n}_{2}\right)$ and $V\left(\tilde{n}_{2} \geq \tilde{n}_{1}\right)$.

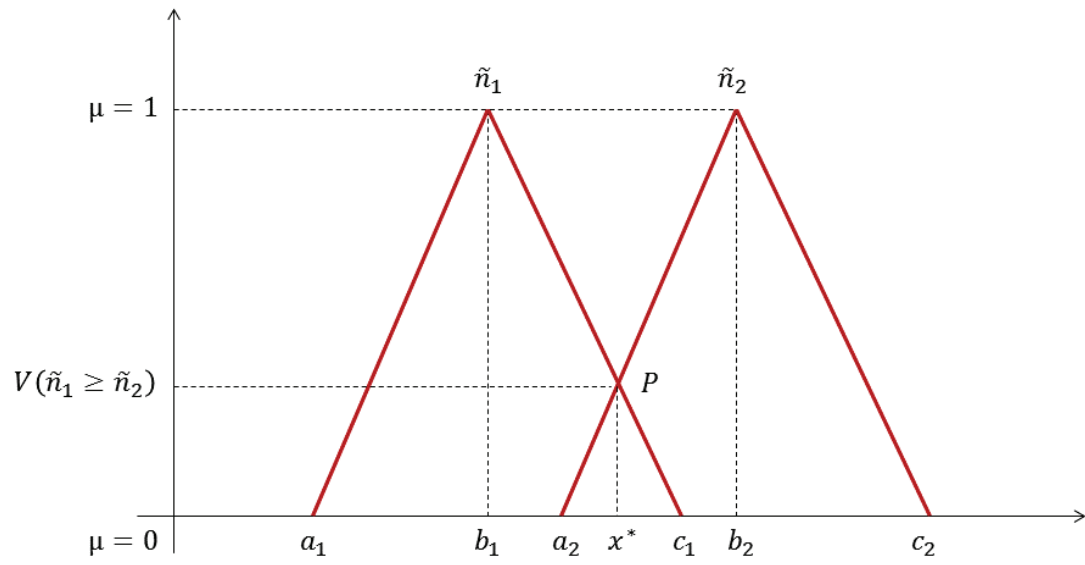

Fig. 4. Representation of the degree of possibility that $\tilde{\boldsymbol{n}}_{\mathbf{1}} \geq \tilde{\boldsymbol{n}}_{\mathbf{2}}$

Furthermore, the possibility degree that a fuzzy number $\tilde{n}$ is greater than $k$ fuzzy numbers $\tilde{n}_{i}(i=1 \ldots k)$ corresponds to:

$$
V\left(\tilde{n} \geq \tilde{n}_{1}, \tilde{n}_{2}, \ldots, \tilde{n}_{k}\right)=V\left[\left(\tilde{n} \geq \tilde{n}_{1}\right) \text { and }\left(\tilde{n} \geq \tilde{n}_{2}\right) \text { and } \ldots \text { and }\left(\tilde{n} \geq \tilde{n}_{k}\right)\right]=\min V\left(\tilde{n} \geq \tilde{n}_{i}\right), i=1 \ldots k .
$$

Then, it is possible to link each criterion (or alternative) $X_{i}$ considered in the FPCM $\tilde{X}$ to the relative value of fuzzy synthetic extent and to define:

$$
x^{*^{\prime}}\left(X_{i}\right)=\min V\left(S_{i} \geq S_{k}\right)
$$

for $k=1 \ldots n, k \neq i$. The vector of crisp and not normalized weights is lastly given by:

$$
W^{\prime}=\left(x^{*^{\prime}}\left(X_{1}\right), x^{*^{\prime}}\left(X_{2}\right), \ldots, x^{*^{\prime}}\left(X_{n}\right)\right)^{T}
$$

Let us observe that these obtained weights have to be normalized with respect to their total so that their sum equals one; the vector of normalized crisp weights will be:

$$
W=\left(x^{*}\left(X_{1}\right), x^{*}\left(X_{2}\right), \ldots, x^{*}\left(X_{n}\right)\right)^{T} .
$$


The last operation consists in checking the consistency ratio (CR) of the collected comparisons. To such an aim, each fuzzy value $\tilde{x}_{i j}$ of the matrix is defuzzified and transformed into a crisp value $x_{i j}(18)$ by means of the graded mean integration approach:

$$
G\left(\tilde{x}_{i j}\right)=x_{i j}=\frac{x_{1}+4 x_{2}+x_{3}}{6} .
$$

After having defuzzified each value of the matrix, consistency can be easily verified with the proper threshold (Saaty, 1977).

\subsection{The ELECTRE III to rank results of data processing analyses}

Originally born in France during the end of the 1960s (Roy, 1968), ELECTRE methods are fundamentally based on the so called outranking approach (Roy, 1991), seeking to establish outranking relations by pairwise comparing alternatives. These relations need to be examined and confirmed by means of two tests, namely the concordance and the discordance tests, aimed at calculating the concordance and discordance indices. The concordance index $C_{i j}$ quantitatively expresses, referring to a specific criterion, the agreement degree about the fact that alternative $A_{i}$ outranks or equals alternative $A_{j}$. The discordance index $D_{i j}$ quantitatively expresses, referring to a specific criterion, the agreement degree about the fact that alternative $A_{i}$ has a worst score compared to alternative $A_{j}$. Various versions of the ELECTRE methods have been proposed (Rogers et al., 2013).

The ELECTRE III method is herein applied to rank different GPR images (i.e. alternatives) to effectively support the maintenance management of WSSs. This method considers a fuzzy outranking; it is neither expressed as a certain outranking nor as a certain non-outranking for each pair of compared alternatives. It has actually associated the function $\delta\left(A_{i}, A_{j}\right)$, varying into the range [0,1], to express the degree of credibility related to the preference of alternative $A_{i}$ with respect to alternative $A_{j}$. The ELECTRE III method requires the preliminary collection of the following input data: 1 ) set of alternatives, $A_{i}$, to be evaluated; 2) evaluation criteria, $B_{k} ; 3$ ) vector of criteria weights, $\left.w_{k} ; 4\right)$ numerical evaluation of alternatives with respect to the considered criteria, $u_{k}\left(A_{i}\right)$.

Moreover, three numerical thresholds (Table 1) have to be fixed for each criterion. These thresholds enable to take into account data uncertainty affecting alternatives. They refer to the difference $u_{k}\left(A_{j}\right)-u_{k}\left(A_{i}\right)$, which is the difference between numerical evaluation of two alternatives $A_{i}$ and $A_{j}$ under the criterion $B_{k}$.

The condition $I_{k} \leq S_{k} \leq V_{k}$ has always to be verified. Once collected input data in a matrix and fixed the mentioned thresholds for all criteria, the development of the procedure is organized in two phases.

\section{Table 1}

Thresholds of the ELECTRE III method

\begin{tabular}{|c|c|c|}
\hline Symbol & Threshold & Meaning \\
\hline$I_{k}$ & Indifference & $\begin{array}{l}\text { the minimal difference considered significant to express a } \\
\text { preference between two alternatives; }\end{array}$ \\
\hline$S_{k}$ & Strong Preference & $\begin{array}{l}\text { the minimal difference to express a strong preference between two } \\
\text { alternatives; }\end{array}$ \\
\hline$V_{k}$ & Veto & $\begin{array}{l}\text { if this minimal difference is overcome, the two alternatives are } \\
\text { considered not comparable. }\end{array}$ \\
\hline
\end{tabular}

The $1^{\text {st }}$ PHASE is made up of four steps explained next.

- Construction of the matrices $C_{k}\left(A_{i}, A_{j}\right)$ of concordance indices, one for each criterion.

Concordance indices are determined by following the rules $(19,20)$ :

if $\quad u_{k}\left(A_{i}\right) \geq u_{k}\left(A_{j}\right)$, then $C_{k}\left(A_{i}, A_{j}\right)=1 ;$
if $\quad u_{k}\left(A_{i}\right)<u_{k}\left(A_{j}\right)$, then $C_{k}\left(A_{i}, A_{j}\right)=\left\{\begin{array}{cl}\frac{\left[u_{k}\left(A_{i}\right)+S_{k}-u_{k}\left(A_{j}\right)\right]}{S_{k}-I_{k}} & \text { if } u_{k}\left(A_{j}\right)-u_{k}\left(A_{i}\right) \leq I_{k} ; \\ 0 & \text { if } u_{k}\left(A_{j}\right)-u_{k}\left(A_{j}\right)-u_{k}\left(A_{i}\right) \leq S_{k} .\end{array}\right.$

The output of the first step will be a number of square matrices equal to the number of criteria, and, in each matrix, the concordance indices $C_{k}\left(A_{i}, A_{j}\right)$ are obtained for each pairwise comparison.

- Construction of the aggregated concordance matrix $C\left(A_{i}, A_{j}\right)$. 
The output of the second step will be a single square matrix $C\left(A_{i}, A_{j}\right)$ in which the elements are obtained by aggregating and weighting the relative elements belonging to the former matrices of concordance indices.

- Construction of the matrices $D_{k}\left(A_{i}, A_{j}\right)$ of discordance indices, one for each criterion.

Discordance indices are determined by following the rules expressed by (21):

$$
D_{k}\left(A_{i}, A_{j}\right)=\left\{\begin{array}{cl}
0 & \text { if } C_{k}\left(A_{i}, A_{j}\right) \neq 0 ; \\
\frac{\left[u_{k}\left(A_{j}\right)-u_{k}\left(A_{i}\right)-S_{k}\right]}{V_{k}-S_{k}} & \text { if } S_{k} \leq u_{k}\left(A_{j}\right)-u_{k}\left(A_{i}\right)<V_{k} \\
1 & \text { if } u_{k}\left(A_{j}\right)-u_{k}\left(A_{i}\right) \geq V_{k}
\end{array}\right.
$$

The output of the third step will be a number of square matrices equal to the number of criteria; in each matrix, the discordance indices $D_{k}\left(A_{i}, A_{j}\right)$ are obtained for each pairwise comparison.

- Construction of the outranking credibility matrix $\delta\left(A_{i}, A_{j}\right)$.

The last step of the $1^{\text {st }}$ PHASE requires the calculation of the outranking credibility matrix, $\delta\left(A_{i}, A_{j}\right)$. The rules to build this matrix are the following (22-24):

if $\forall k D_{k}\left(A_{i}, A_{j}\right)=0$, then $\delta\left(A_{i}, A_{j}\right)=C\left(A_{i}, A_{j}\right)$;

if $\exists k$ for which $D_{k}\left(A_{i}, A_{j}\right)>0$, then $\delta\left(A_{i}, A_{j}\right)=C\left(A_{i}, A_{j}\right)$ if $\forall k \quad D_{k}\left(A_{i}, A_{j}\right)<C\left(A_{i}, A_{j}\right)$;

if $\exists k^{*}$ for which $D_{k^{*}}\left(A_{i}, A_{j}\right) \geq C\left(A_{i}, A_{j}\right)$, then $\delta\left(A_{i}, A_{j}\right)=C\left(A_{i}, A_{j}\right) \cdot \prod_{k^{*}} \frac{\left[1-D_{k^{*}}\left(A_{i}, A_{j}\right)\right]}{\left[1-C\left(A_{i} A_{j}\right)\right]} \forall k^{*}$.

The output will be a square matrix in which elements express the degree of credibility related to the preference of the alternative $A_{i}$ with respect to $A_{j}$.

Once the $1^{\text {st }}$ PHASE is accomplished, the $2^{\text {nd }}$ PHASE is composed of three steps.

- Determination of the minimal value of outranking credibility, $\delta_{0}$.

The minimal value of outranking credibility corresponds to:

$\delta_{0}=\delta_{\max }-s\left(\delta_{\max }\right)$

where $\delta_{\max }$ is the maximum numerical value of the elements belonging to the outranking credibility matrix $\delta\left(A_{i}\right.$ , $\left.A_{j}\right)$, and $s\left(\delta_{\text {max }}\right)$, called discrimination threshold, is obtained by:

$s\left(\delta_{\max }\right)=-0.15 \cdot \delta_{\max }+0.3$

- Construction of the Boolean matrix $T\left(A_{i}, A_{j}\right)$.

This Boolean matrix is built on the basis of the test (27):

$T\left(A_{i}, A_{j}\right)=\left\{\begin{array}{l}1 \quad \text { if } \delta\left(A_{i}, A_{j}\right) \geq \delta_{0} \text { and } \delta\left(A_{i}, A_{j}\right)-\delta\left(A_{j}, A_{i}\right)>s\left(\delta_{\max }\right) \\ 0 \text { otherwise }\end{array}\right.$.

The purpose is to define the qualification degree of the alternatives and build the ranking.

- Qualification degree of alternatives and construction of the final ranking.

The qualification of alternative $A_{i}, q\left(A_{i}\right)$, corresponds to the difference between the number of alternatives outranked by $A_{i}$ and the number of alternatives outranking $A_{i}$. Finally, two rankings have to be built by means of two procedures of distillation (ascending and descending distillation chains, Vincke, 1992), which consist in deleting the row and column from the outranking credibility related to the alternative characterized by the highest and lowest qualification degree, respectively, and in reiterating the $2^{\text {nd }}$ PHASE until all the alternatives have been assigned in both rankings. With relation to the two procedures of distillation, if two alternatives are characterized by the same qualification degree, a distillation procedure would have to be carried out just for the two rows and columns related to the two alternatives of the outranking credibility matrix $\delta\left(A_{i}, A_{j}\right)$. To obtain a ranking of the entire alternative set, these two rankings must coincide. If they were not equal, it would mean that incomparability among alternatives occurs.

\section{Case study}

In Carpitella et al. (2017b) the ELECTRE I method was applied to select the best alternative with relation to a set of four GPR images $\left(\mathrm{HF}_{1}, \mathrm{HF}_{2}, \mathrm{HF}_{3}, \mathrm{HF}_{4}\right)$, presented in Figure 5 and representing the outputs of the data 
processing techniques previously described in section 2 . The present case study aims to achieve the final ranking of the same alternatives, by considering one more evaluation criterion, namely the economic aspect in carrying out different data processing analyses.

Therefore, alternatives are now evaluated on the basis of five criteria $\left(\mathrm{B}_{1}, \mathrm{~B}_{2}, \mathrm{~B}_{3}, \mathrm{~B}_{4}, \mathrm{~B}_{5}\right)$ : visualization, interpretation, identification of features, extraction of information and affordability. All evaluation criteria have to be maximized and their weights are herein obtained by means of the FAHP technique, in order to better manage uncertainty of evaluations. Upon the FAHP, the ELECTRE III is applied to rank the four GPR images.

\subsection{The FAHP to calculate criteria weights}

An expert in image mining processing analysis was asked to draw up a fuzzy pairwise comparison matrix (Table 2) for the criteria by attributing judgments using the linguistic variables defined in Figure 3.

Table 2

Fuzzy Pairwise Comparison Matrix

\begin{tabular}{ccccccc}
\hline$\tilde{\boldsymbol{X}}$ & $\mathbf{B}_{\mathbf{1}}$ & $\mathbf{B}_{\mathbf{2}}$ & $\mathbf{B}_{\mathbf{3}}$ & $\mathbf{B}_{\mathbf{4}}$ & $\mathbf{B}_{\mathbf{5}}$ & weights \\
\hline $\mathbf{B}_{\mathbf{1}}$ & $(1,1,2)$ & $(1,2,3)$ & $(3,4,5)$ & $(1,2,3)$ & $(1,2,3)$ & 0.2934 \\
$\mathbf{B}_{\mathbf{2}}$ & $\left(\frac{1}{3}, \frac{1}{2}, 1\right)$ & $(1,1,2)$ & $(2,3,4)$ & $(1,2,3)$ & $\left(\frac{1}{3}, \frac{1}{2}, 1\right)$ & 0.2226 \\
$\mathbf{B}_{\mathbf{3}}$ & $\left(\frac{1}{5}, \frac{1}{4}, \frac{1}{3}\right)$ & $\left(\frac{1}{4}, \frac{1}{3}, \frac{1}{2}\right)$ & $(1,1,2)$ & $(1,2,3)$ & $\left(\frac{1}{3}, \frac{1}{2}, 1\right)$ & 0.1380 \\
$\mathbf{B}_{\mathbf{4}}$ & $\left(\frac{1}{3}, \frac{1}{2}, 1\right)$ & $\left(\frac{1}{3}, \frac{1}{2}, 1\right)$ & $\left(\frac{1}{3}, \frac{1}{2}, 1\right)$ & $(1,1,2)$ & $\left(\frac{1}{3}, \frac{1}{2}, 1\right)$ & 0.1109 \\
$\mathbf{B}_{\mathbf{5}}$ & $\left(\frac{1}{3}, \frac{1}{2}, 1\right)$ & $(1,2,3)$ & $(1,2,3)$ & $(1,2,3)$ & $(1,1,2)$ & 0.2351 \\
\hline
\end{tabular}
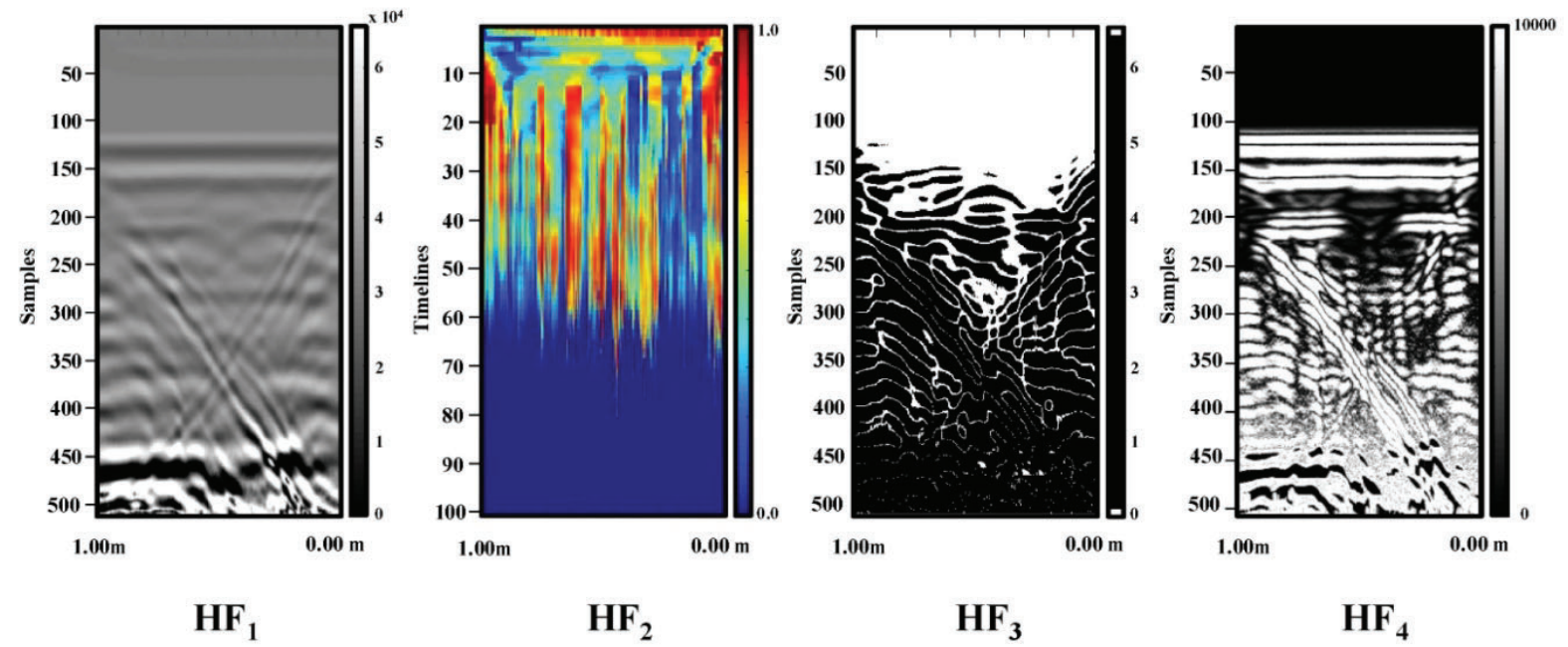

Fig. 5. GPR images resulting from: raw image analysis $\left(\mathrm{HF}_{1}\right)$, multi-agent system $\left(\mathrm{HF}_{2}\right)$, subtraction method $\left(\mathrm{HF}_{3}\right)$, variance filter $\left(\mathrm{HF}_{4}\right)$

The values of fuzzy synthetic extent for each criterion can be calculated by using formula (12):

$$
\begin{aligned}
& S_{1}=(7.00,11.00,16.00) \odot\left(\frac{1}{51.82}, \frac{1}{32.58}, \frac{1}{21.12}\right)=(0.14,0.34,0.76) \\
& S_{2}=(4.67,7.00,11.00) \odot\left(\frac{1}{51.82}, \frac{1}{32.58}, \frac{1}{21.12}\right)=(0.09,0.21,0.52) ; \\
& S_{3}=(2.78,4.08,6.83) \odot\left(\frac{1}{51.82}, \frac{1}{32.58}, \frac{1}{21.12}\right)=(0.05,0.13,0.32) ; \\
& S_{4}=(2.33,3.00,6.00) \odot\left(\frac{1}{51.82}, \frac{1}{32.58}, \frac{1}{21.12}\right)=(0.05,0.09,0.28) \\
& S_{5}=(4.33,7.50,12.00) \odot\left(\frac{1}{51.82}, \frac{1}{32.58}, \frac{1}{21.12}\right)=(0.08,0.23,0.57)
\end{aligned}
$$


These values have to be compared and the relative degrees of possibility, summarized in Table 3 , are calculated by means of formula (13).

Table 3

Degrees of possibility to compare values of fuzzy synthetic extent

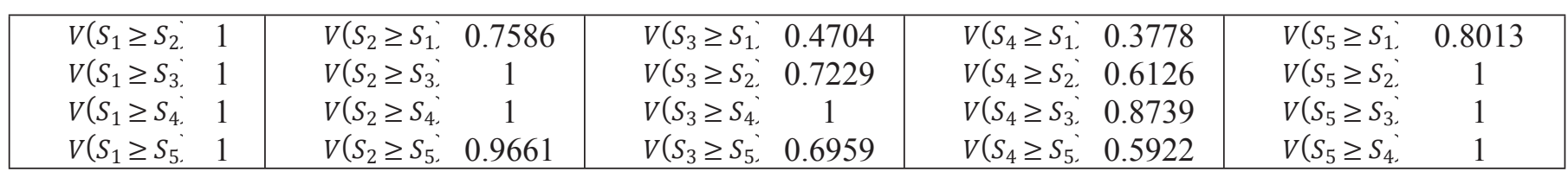

The components of the non-normalized vector of weights $W^{\prime}=\left(x^{*^{\prime}}\left(B_{1}\right), x^{*^{\prime}}\left(B_{2}\right), x^{*^{\prime}}\left(B_{3}\right), x^{*^{\prime}}\left(B_{4}\right), x^{*^{\prime}}\left(B_{5}\right)\right)^{T}$ are calculated through (15):

$$
\begin{aligned}
& x^{\prime}\left(\mathrm{B}_{1}\right)=V\left(S_{1} \geq S_{2}, S_{3}, S_{4}, S_{5}\right)=\min (1 ; 1 ; 1 ; 1)=1 ; \\
& x^{*^{\prime}}\left(\mathrm{B}_{2}\right)=V\left(S_{2} \geq S_{1}, S_{3}, S_{4}, S_{5}\right)=\min (0.7586 ; 1 ; 1 ; 0.9661)=0.7586 ; \\
& x^{*^{\prime}}\left(\mathrm{B}_{3}\right)=V\left(S_{3} \geq S_{1}, S_{2}, S_{4}, S_{5}\right)=\min (0.4704 ; 0.7229 ; 1 ; 0.6959)=0.4704 ; \\
& x^{*^{\prime}}\left(\mathrm{B}_{4}\right)=V\left(S_{4} \geq S_{1}, S_{2}, S_{3}, S_{5}\right)=\min (0.3778 ; 0.6126 ; 0.8739 ; 0.5922)=0.3778 ; \\
& x^{*}\left(\mathrm{~B}_{5}\right)=V\left(S_{5} \geq S_{1}, S_{2}, S_{3}, S_{4}\right)=\min (0.8013 ; 1 ; 1 ; 1)=0.8013 .
\end{aligned}
$$

The obtained normalized vector of weights $W=(0.2934,0.2226,0.1380,0.1109,0.2351)^{T}$ is given in Table 2 .

The last step consists in verifying consistency upon having defuzzified the FPCM by means of the graded mean integration approach (20). In our case, consistency is perfectly acceptable, being the $C R$ index equal to 0.0639 .

\subsection{The ELECTRE III to rank alternatives}

Beyond criteria weights, the input data required to apply the ELECTRE III methodology were collected with the support of the expert mentioned in the former section and are given in Table 4. The scale of evaluations of alternatives under the various criteria is one-to-ten. Figures 6.1 and 6.2 summarize the whole application of the ELECTRE III method. 


\section{$1^{\text {st }}$ PHASE}

Developing an outranking relation characterising the pairwise comparisons between GPR images and accomplishment of the concordance and discordance tests:

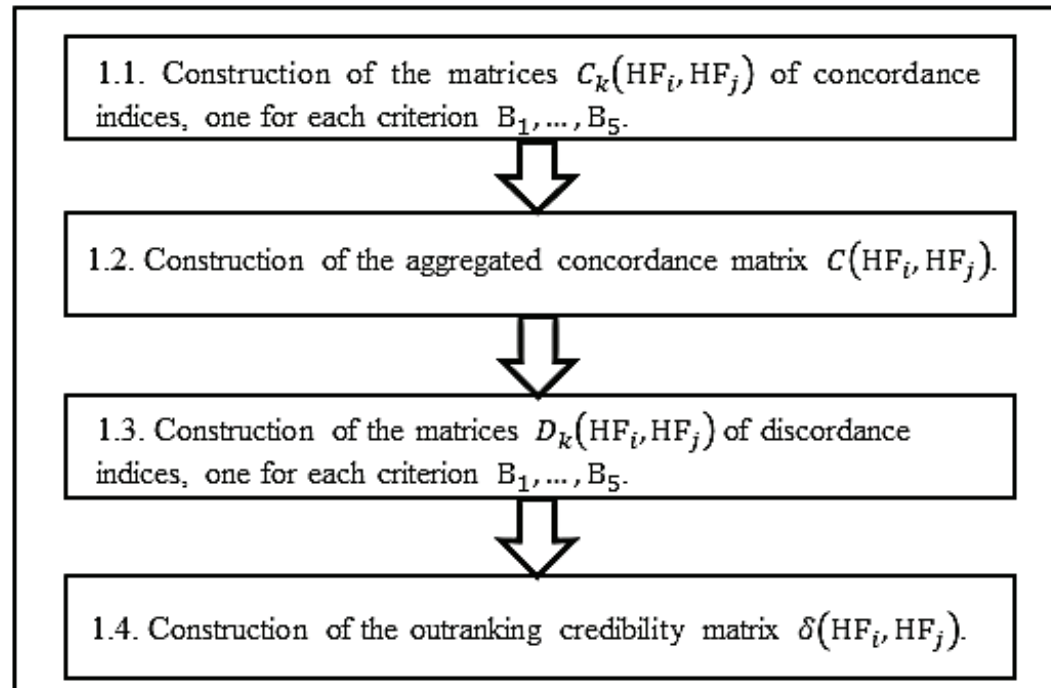

Fig. 6.1. Flowchart representing the application of the first phase of ELECTRE III

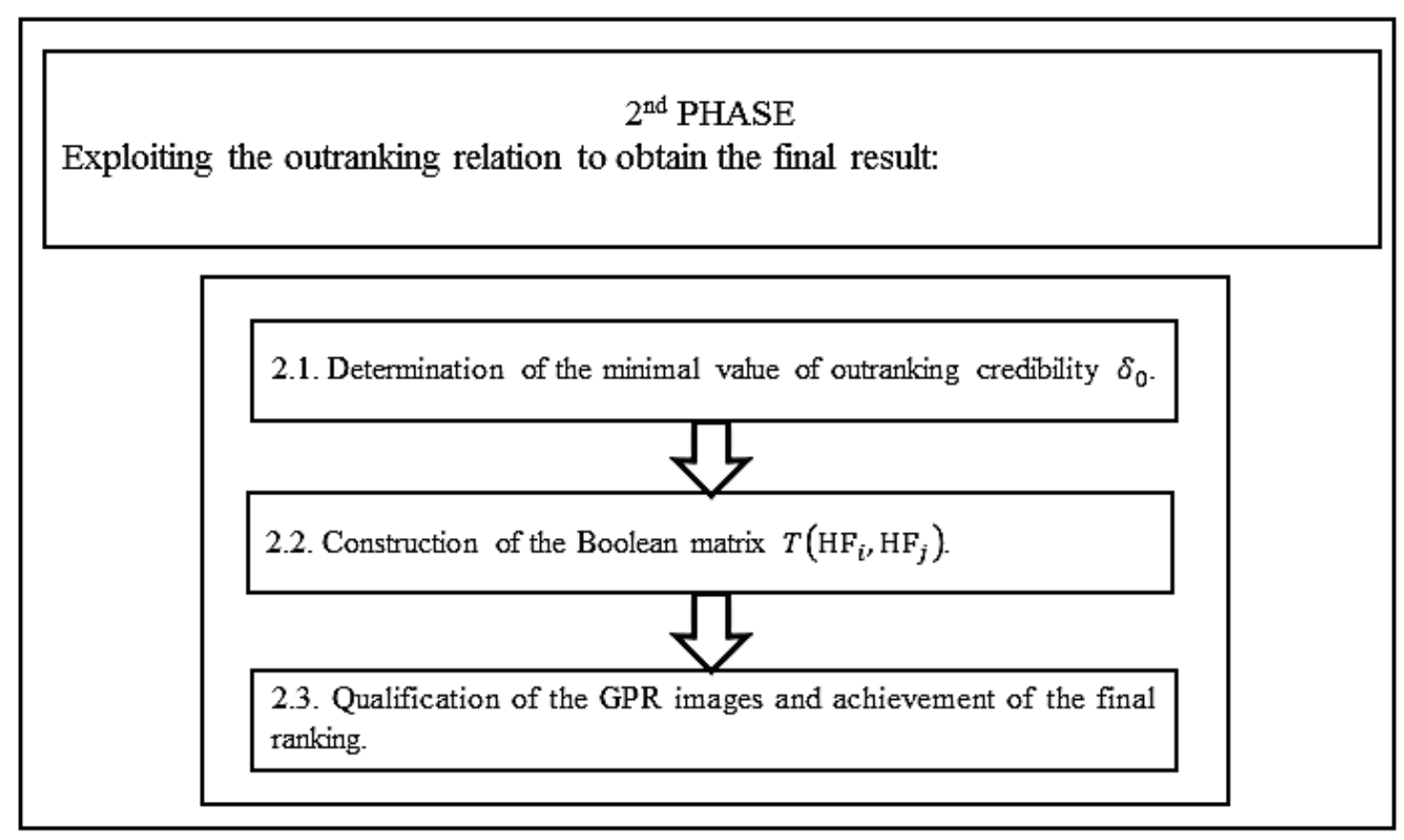

Fig. 6.2. Flowchart representing the application of the second phase of ELECTRE III

The output (Table 5) of the $1^{\text {st }}$ PHASE of the ELECTRE III is the outranking credibility matrix $\delta\left(\mathrm{HF}_{i}, \mathrm{HF}_{j}\right)$, which enables to calculate the minimal value of outranking credibility, that is $\delta_{0}=0.85$, with the purpose of building the Boolean matrix $T\left(\mathrm{HF}_{i}, \mathrm{HF}_{j}\right)$.

The last step of the $2^{\text {nd }}$ PHASE consists of determining the qualification of alternatives $q\left(\mathrm{HF}_{i}\right)$ for the final ranking to be built. These results are reported in Table 6. Since the two distillation procedures (Tables 7 and 8) do not give the same ranking, sub-distillation between $\mathrm{HF}_{1}$ and $\mathrm{HF}_{2}$ is necessary. Thus, the final ranking is reported in Table 9. Both alternatives $\mathrm{HF}_{3}$ and $\mathrm{HF}_{4}$ occupy the first position of the ranking. It means that there is not a significant difference among them. Then, under the perspective of the considered criteria, the application of the subtraction method or of the variance filter is indifferent for supporting and optimizing maintenance activities of WSSs. 
Table 4

Input data of the ELECTRE III

\begin{tabular}{cccccc} 
& $\mathbf{B}_{\mathbf{1}}$ & $\mathbf{B}_{\mathbf{2}}$ & $\mathbf{B}_{\mathbf{3}}$ & $\mathbf{B}_{\mathbf{4}}$ & $\mathbf{B}_{\mathbf{5}}$ \\
\hline weights & 0.2934 & 0.2226 & 0.1380 & 0.1109 & 0.2351 \\
\hline $\boldsymbol{I}_{\boldsymbol{k}}-\boldsymbol{S}_{\boldsymbol{k}}-\boldsymbol{V}_{\boldsymbol{k}}$ & $2-4-6$ & $1-3-5$ & $1-2-3$ & $1-2-3$ & $1-3-5$ \\
\hline $\mathbf{H F}_{\mathbf{1}}$ & 3 & 2 & 6 & 5 & 8 \\
$\mathbf{H F}_{\mathbf{2}}$ & 8 & 5 & 7 & 8 & 4 \\
$\mathbf{H F}_{\mathbf{3}}$ & 7 & 7 & 9 & 5 & 6 \\
$\mathbf{H F}_{\mathbf{4}}$ & 8 & 7 & 8 & 5 & 6 \\
\hline
\end{tabular}

Table 5

Outranking credibility matrix

\begin{tabular}{ccccc}
\hline $\boldsymbol{\delta}\left(\mathbf{H F}_{\boldsymbol{i}}, \mathbf{H F}_{\boldsymbol{j}}\right)$ & $\mathbf{H F}_{\mathbf{1}}$ & $\mathbf{H F}_{\mathbf{2}}$ & $\mathbf{H F}_{\mathbf{3}}$ & $\mathbf{H F}_{\mathbf{4}}$ \\
\hline $\mathbf{H F}_{\mathbf{1}}$ & - & 0 & 0 & 0 \\
$\mathbf{H F}_{\mathbf{2}}$ & 0,7649 & - & 0,63315 & 0,77155 \\
$\mathbf{H F}_{\mathbf{3}}$ & 0,88245 & 0 & - & 1 \\
$\mathbf{H F}_{\mathbf{4}}$ & 0,88245 & 0 & 1 & - \\
\hline
\end{tabular}

Table 6

Qualification of alternatives

\begin{tabular}{cc}
\hline Alternatives & $\boldsymbol{q}\left(\mathbf{H F}_{\boldsymbol{i}}\right)$ \\
\hline $\mathbf{H F}_{\mathbf{1}}$ & -2 \\
$\mathbf{H F}_{\mathbf{2}}$ & 0 \\
$\mathbf{H F}_{3}$ & 1 \\
$\mathbf{H F}_{\mathbf{4}}$ & 1 \\
\hline
\end{tabular}

Table 7

Ascending distillation results

\begin{tabular}{cc}
\hline Alternatives & Position \\
\hline $\begin{array}{c}\mathrm{HF}_{2}, \mathrm{HF}_{3}, \\
\mathrm{HF}_{4}\end{array}$ & $\mathbf{1}^{\circ}$ \\
$\mathrm{HF}_{1}$ & $2^{\circ}$ \\
\hline
\end{tabular}

Table 8

Descending distillation results

\begin{tabular}{cc}
\hline Alternatives & Position \\
\hline $\mathrm{HF}_{3}, \mathrm{HF}_{4}$ & $\mathbf{1}^{\circ}$ \\
$\mathrm{HF}_{2}$ & $\mathbf{2}^{\circ}$ \\
$\mathrm{HF}_{1}$ & $3^{\circ}$ \\
\hline
\end{tabular}


Table 9

Final ranking

\begin{tabular}{cc}
\hline Alternatives & Position \\
\hline $\mathrm{HF}_{3}, \mathbf{H F}_{4}$ & $\mathbf{1}^{\text {st }}$ \\
$\mathrm{HF}_{2}$ & $2^{\text {nd }}$ \\
$\mathrm{HF}_{1}$ & $\mathbf{3}^{\text {rd }}$ \\
\hline
\end{tabular}

\section{Conclusions}

The paper proposes a structured framework based on the combination of two MCDM methods, namely the FAHP and the ELECTRE III, to provide support in selecting the most suitable data processing technique to explore WSS underground and thus help to improve the maintenance management of WSSs. This kind of management can be effectively led by using GPR radargrams as non-destructive technique drivers of critical parts of the networks. The purpose of the research consists in analysing, using a multi-criteria perspective, GPR images obtained from diverse types of data processing analyses.

On the theoretical point of view, being the combination of two MCDM methods a well-established and reliable practice, it can be significant to give a positive contribution in a crucial practical field as the one considered in the paper, also considering uncertainty characterizing human evaluation. On the practical point of view, data processing techniques based on the use of GPR are really useful in providing a graphic overview of the state of buried pipes and components. Since they are often critical for the good operation of WSSs, the role of maintenance is fundamental and the organization of suitable interventions is strategic.

To this aim, upon having established a set of evaluation criteria, the proposed approach makes firstly use of the FAHP technique to determine criteria weights by taking into account and thus reducing uncertainty of human judgments. Additionally, it is suggested the use of ELECTRE III, which is considered as the most reliable in literature among the methods belonging to the ELECTRE family. Actually, the ranking of GPR radargrams evaluated through ELECTRE III provides interesting information concerning which data processing method is more suitable to optimize the maintenance management of WSSs.

The proposed structured approach has been applied to a real case study, whose alternatives have been derived from four kinds of data processing analyses, namely, raw image analysis, multi-agent system, subtraction method and variance filter. Five evaluation criteria are aimed at considering these analyses both under the technical and the economic point of view. The two most suitable alternatives, both in the first position of the final ranking, are the GPR images reached by the variance filter and the subtraction methods. This ranking demonstrates that the application of the variance filter or the subtraction method equivalently represents the best trade-off among the considered criteria.

The present paper is an extension of a previous research (Carpitella et al., 2017b), in which the ELECTRE I method was applied to select the best alternative (all that this method permits), which resulted to be the image obtained through the variance filter. Moreover, in Carpitella et al. (2017b) the weights were merely attributed by the expert. Now, by means of the application of the FAHP we asked the expert to attribute judgments about the importance between pairs of criteria and considered a wider set of criteria by taking into consideration the presence of uncertainty. As a result, another solution, namely the subtraction method, may be considered as the most suitable, as shown in Table 9.

Even more accurate and meaningful results can be achieved by adequately combining different methods of data processing analysis. Indeed, such integration would permit to exploit strengths of different analyses and to sharpen the process of abnormality location in WSSs.

Possible developments of this research will consider the application of other different GPR techniques and the elaboration of a detailed scheduling of maintenance activities on the basis of a further integration between the already proposed MCDM approach and a multi-objective optimization point of view.

\section{Acknowledgements}

Part of this work has been developed under the support of the UPV mobility program for PhD students, awarded to the first author, and of Fundación Carolina PhD, within its short stage scholarship program awarded to the second author.

\section{References}

Abedi, M., Torabi, S.A., Norouzi, G.H., Hamzeh, M. (2012). ELECTRE III: A knowledge-driven method for integration of geophysical data with geological and geochemical data in mineral prospectivity mapping. Journal of Applied Geophysics, 87, 9-18. 
Ayala-Cabrera, D., Izquierdo, J., Ocaña-Levario, S.J., Pérez-García, R. (2014). 3D model construction of water supply system pipes based on GPR images. Proceedings of the 7th International Congress on Environmental Modeling and Software (iEMSs), CA, USA.

Ayala-Cabrera, D., Ocaña-Levario, S.J., Pérez-García, R., Izquierdo, J., Herrera, M. (2013a). Visualización de fugas de agua en sistemas de abastecimiento de agua mediante imágenes de GPR. Proceedings of XII Simposio Iberoamericano sobre Abastecimiento de Agua y Drenaje Urbano (SEREA 2013), Buenos Aires, Argentina.

Ayala-Cabrera, D., Izquierdo, J., Montalvo, I., Pérez-García, R. (2013). Water supply system component evaluation from GPR radargrams using a multi-agent approach. Mathematical and Computer Modeling, 57 (7) 1927 1932.

Ayala-Cabrera, D., Herrera, M., Izquierdo, J., Pérez-García, R. (2011). Location of buried plastic pipes usingmulti-agent support base don GPR images. Journal of Applied Geophysics, 75, 679-686.

Bimpas, M., Amditis, A., Uzunoglu, N. (2010). Detection of water leaks in supply pipes using continuous wave sensor operating at $2.45 \mathrm{GHz}$. Journal of Applied Geophysics, 70, 226-236.

Büyüközkan, G., Çifçi, G. (2012).A combined fuzzy AHP and fuzzy TOPSIS based strategic analysis of electronic service quality in healthcare industry. Expert Systems with Applications, 39 (3) 2341-2354.

Büyüközkan, G., Çifçi, G., Güleryüz, S. (2011). Strategic analysis of healthcare service quality using fuzzy AHP methodology. Expert Systems with Applications, 38 (8) 9407-9424.

Carpitella, S., Certa, A., Izquierdo, J., La Fata, CM. (2017a). k-out-of-n systems: an exact formula for stationary availability and multi-objective configuration design based on mathematical programming and TOPSIS. Journal of Computational and Applied Mathematics, In Press.

Carpitella, S., Ocana-Levario, S.J., Benítez, J., Certa, A., Enea, M., Izquierdo, J. (2017b). The ELECTRE I method to optimise GPR data processing analyses for maintenance of water networks. Proceedings of 23th ISSAT International Conference on Reliability and Quality in Design, Chicago, Illinois, USA. (Accepted)

Certa A., Enea M., Galante G., Lupo T. (2013 a). A multi-decision makers approach to select the maintenance plan for a multi-component system. Proceeding of 19 th ISSAT International Conference on Reliability and Quality in Design, Honolulu, Hawai, USA.

Certa, A., Enea, M., Lupo, T. (2013 b). ELECTRE III to dynamically support the decision maker about the periodic replacements configurations for a multi-component system. Decision Support System , 55 (1) 126-134.

Certa, A., Enea, M., Galante, G., La Fata, C.M. (2009). Multi-objective human resources allocation in R\&D projects planning. International Journal of Production Research, 47 (13) 3503-3523.

Chang, D.-Y. (1996). Application of the extent analysis method on fuzzy AHP. European Journal of Operational Research, 95, 649-655.

Chen, S.-M., Wu, Y.-M., Yang, L. (2014). Application of the Analytic Hierarchy Process for the selection of wastewater reuse targets. Management Decision, 52 (7), 1222-1235.

Crocco, L., Soldovieri, F., Millington, T., Cassidy, N.J. (2010). Bistatic Tomographic GPR imaging for incipient pipeline leakage evaluation. Progress in Electromagnetics Research, 101, 307-321.

Demirci, S., Yigit, E., Eskidemir, I.H., Ozdemir, C. (2012). Ground penetrating radar imaging of water leaks from buried pipes based on back-projection method. NDT\&E International, 47, 35-42.

Dong, L., Carnalla, S., Shinozuka, M. (2011). Experimental and analytical study of detecting leakage of water pipes using ground-penetrating radar. Proceedings of the 9th International workshop on remote sensing for disaster response, Standford, California, USA.

Durán, O., Aguiló, J. (2006). Selección de máquinas de control numérico usando Fuzzy AHP. Espacios, 27 (1). http://www2.scielo.org.ve/scielo.php?script=sci arttext\&pid=S0798-10152006000100006\&lng=es\&nrm=iso. ISSN 0798-1015.

Figueira, J.R., Greco, S., Roy, B., Slowinski, R. (2013). An overview of ELECTRE methods and their recent extensions. Journal of Multi-Criteria Decision Analysis, 20, 61-85.

Govindan, K., Jepsen, M.B. (2016). ELECTRE: A comprehensive literature review on methodologies and applications. European Journal of Operational Research, 250 (1) 1-29. 
Gurbuz, A.C., McClellan, J.H., Scott, W.R. (2012). Compressive sensing of underground structures using GPR. Digital Signal Processing, 22 (1) 66-73.

Hao, T., Rogers, C.D.F., Metje, N., Chapman, D.N., Muggleton, J.M., Foo, K.Y., Wang, P., Pennock, S.R., Atkins, P.R., Swingler S.G., Parker, J., Costello, S.B., Burrow, M.P.N., Anspach, J.H., Armitage, R.J, Cohn, A.G., Goddard, K., Lewin, P.L., Orlando, G., Redfern, M.A., Royal, A.C.D., Saul, A.J. (2012). Condition assessment of the buried utility service infrastructure, Tunnelling and Underground Space Technology, 28, 331-344.

Hatami-Marbini, A., Tavana, M. (2011). An extension of the Electre I method for group decision-making under a fuzzy environment; Omega, 39 (4) 373-386.

Hoarau, Q., Ginolhac, G., Atto, A.M., Nicolas, J.M. (2017). Robust adaptive detection of buried pipes using GPR. Signal Processing, 132, 293-305.

Hokkanen, J., Salminen, P., Rossi, E., Ettala, M. (1995). The choice of a solid waste management system using the Electre II decision-aid method. Waste Management \& Research, 13 (2) 175-193.

Hunaidi, O., Giamou, P. (1998). Ground-penetrating radar for detection of leaks in buried plastic water distribution pipes. Proceedings of the seventh International Conference on Ground-Penetrating Radar, Lawrence, Kansas, USA.

Jun, D., Tian-tian, F., Yi-sheng, Y., Yu, M. (2014). Macro-site selection of wind/solar hybrid power station based on ELECTRE-II. Renewable and Sustainable Energy Reviews, 35, 194-204.

Ka, B. (2011). Application of Fuzzy AHP and ELECTRE to China Dry Port Location Selection. The Asian Journal of Shipping and Logistics, 27 (2) 331-353.

Kaya, T., Kahraman, C. (2011). An integrated fuzzy AHP-ELECTRE methodology for environmental impact assessment. Expert Systems with Applications, 38 (7) 8553-8562.

Klir, G.J., Yuan, B. (1995). Fuzzy sets and fuzzy logic - Theory and applications. Prentice Hall PTR, Upper Saddle River, New Jersey.

Kubler, S., Robert, J., Derigent, W., Voisin, A., Le Traon, Y. (2016). A state-of the-art survey \& testbed of fuzzy AHP (FAHP) applications. Expert Systems with Applications, 65, 398-422.

Kumar, A., Sah, B., Singh, A.R., Deng, Y., He, X., Kumar, P., Bansal, R.C. (2017). A review of multi criteria decision making $(\mathrm{MC} \backslash \mathrm{DM})$ towards sustainable renewable energy development. Renewable and Sustainable Energy Reviews, 69, 596-609.

Kutlu, A.C., Ekmek ioğlu, M. (2012). Fuzzy failure modes and effects analysis by using fuzzy TOPSIS-based fuzzy AHP. Expert Systems with Applications, 39 (1) 61-67.

La Scalia, G., Micale, R., Certa, A., Enea, M. (2015). Ranking of shelf life models based on smart logistic unit using the ELECTRE III method. International Journal of Applied Engineering Research, 10 (17) 3800938015 .

Liu, Z., Kleiner, Y. (2013). State of the art review of inspection technologies for condition assessment of water pipes. Measurement, 46(1) 1-15.

Løken, E. (2007).Use of multicriteria decision analysis methods for energy planning problems. Renewable and Sustainable Energy Reviews, 11 (7) 1584-1595.

Mousavi-Nasab, S.H., Sotoudeh-Anvari, A. (2017). A comprehensive MCDM-based approach using TOPSIS, COPRAS and DEA as an auxiliary tool for material selection problems. Materials \& Design, 121, 237-253.

Mulliner, E., Malys, N., Maliene, V. (2016). Comparative analysis of MCDM methods for the assessment of sustainable housing affordability. Omega, 59, 146-156.

Muñoz-Porcar, A., Alonso-Nuez, M.J., Flores-García, M., Duret-Solanas, D. (2015). The renewal of assets using a tool to aid decision making. Management Decision, 53 (7), 1412-1429.

Nikas, A., Doukas, H., López, L.M. (2018). A group decision making tool for assessing climate policy risks against multiple criteria. Heliyon, 4 (3), https://doi.org/10.1016/j.heliyon.2018.e00588.

Ocaña-Levario, S.J. (2014). Reconocimiento de patrones para la identificación de tuberías enterradas en sistemas de abastecimiento de agua a partir de imágenes de GPR. Tesis de Máster, Universitat Politècnica de València, Valencia, Spain. 
Ocaña-Levario, S.J., Ayala-Cabrera, D., Izquierdo, J., Pérez-García, R. (2016). Análisis de imágenes de georadar para la localización de fugas mediante la aplicación de filtros de varianza. Proceedings of the XII Seminario euro-Latinoamericano de Sistemas de Ingeniería (SELASI), Lleida, España.

Porsani, J.L., Sauck, W.A., Júnior, A.O.S. (2006). GPR for mapping fractures and as a guide for the extraction of ornamental granite from a quarry: A case study from southern Brazil. Journal of Applied Geophysics, 58 (3) $177-187$.

Proulx, F., Rodriguez, M.J., Sérodes, J., Bouchard, C. (2007). A methodology for identifying vulnerable locations to taste and odour problems in a drinking water system. Water Science and Technology, 55 (5) 177-183.

Roy, B. (1991). The outranking approach and the foundations of electre methods. Theory and Decision, 31, 1, 4973.

Roy, B. (1968). Classement et choix en presence de points de vue multiples (La methode ELECTRE). Revue Francaise D Informatique de Recherche Operationnelle, 2 (8) 57-75.

Rogers, M.G., Bruen, M., Maystre, L-Y. (2013). ELECTRE AND DECISION SUPPORT. Methods and Applications in Engineering and Infrastructure Investment.

Saaty, T.L. (1977). A scaling method for priorities in hierarchical structures. Journal of Mathematical Psychology, 15 (3) 234-281.

Shoham, K., Leyton-Brown, K. (2009). Multiagent Systems: Algorithmic, Game-Theoretic and Logical Foundations. Cambridge University Press, Cambridge, MA, USA.

Sipahi, S., Timor, M. (2010). The analytic hierarchy process and analytic network process: An overview of applications. Management Decision, 48 (5) 775-808.

Thomson, J., Wang, L., Royer, M. (2009). State of technology review report on condition assessment of ferrous water transmission and distribution systems. EPA United States Environmental Protection Agency, EPA/600/R-09/055.

Van Laarhoven, P., Pedrycz, W. (1983). A fuzzy extension of Saaty's priority theory. Fuzzy Sets and Systems, 11 (1) 199-227.

Vincke, P. (1992). Multicriteria Decision-Aid. Wiley.

Wang, P., Zhouquan Zhu, Z., Wang, Y. (2016). A novel hybrid MCDM model combining the SAW, TOPSIS and GRA methods based on experimental design. Information Sciences, 345, 27-45.

Zadeh, L. (1965). Fuzzy sets. Information and Control, 8, 338-353.

Zimmermann, H.J. (1985). Fuzzy set theory and its applications. Kluwer, Boston, MA. 